\title{
O ENCANTO PELA BIBLIOTECONOMIA: RELATO DE EXPERIÊNCIA DE DOCÊNCIA VOLUNTÁRIA
}

\author{
Jorge Santa Anna \\ Mestrando do PPG em Gestão e Organização do Conhecimento - UFMG \\ jorjao20@yahoo.com.br
}

Resumo

\begin{abstract}
A Biblioteconomia é uma área de conhecimento que encanta. Isso se justifica por diversos motivos. Merece destaque o fato de que o fazer profissional biblioteconômico perpassa todas as demais áreas do conhecimento, contribuindo na organização e disseminação das informações produzidas em quaisquer campos científicos, o que viabiliza, naturalmente, a aquisição de conhecimentos variados por parte do bibliotecário. A partir dessa afirmação, este artigo relata o iniciar da carreira profissional de um bibliotecário, por meio de sua atuação como professor voluntário. Discorre o contexto de vinculação do professor ao Curso de Biblioteconomia, como também os recursos didáticos, os procedimentos de ensino adotados e as atividades realizadas em sala de aula, mediante o lecionamento da disciplina Formação e Desenvolvimento de Coleções. Ao final, atesta as contribuições da experiência, mencionando os benefícios alcançados tanto pelo professor quanto pelo alunado e as expectativas para o ingresso no mercado de trabalho.
\end{abstract}

Palavras-chave: Docência-Biblioteconomia. Ensino pela pesquisa. Prática profissional. Gestão de coleções.

\section{INTRODUÇÃO}

Construir uma carreira profissional de sucesso representa um longo processo, permeado por um conjunto de atividades, vivências e decisões complexas e instáveis. O percorrer desse caminho se traduz, para muitos, como uma das escolhas decisivas da vida, manifestando-se, praticamente, como uma morosa batalha.

Independente das diferentes circunstâncias a que somos submetidos no decorrer da trajetória de uma profissão, não resta dúvida que um dos fatores mais influentes para se alcançar o sucesso diz respeito à satisfação, à motivação, ao gosto, à realização por aquilo que se faz.

É bem evidente que: profissional satisfeito se torna mais empenhado, mais engajado, logo, mais produtivo e competente! É claro que outros fatores também se manifestam, sobretudo no que se refere às oportunidades que ora surgem, à valorização por parte do mercado de trabalho, às condições para execução das atividades profissionais, à remuneração recebida, dentre outros.

Mas, de qualquer forma, defendemos a tese de que a satisfação é o maior influenciador no desenvolvimento e sucesso de um profissional. $\mathrm{O}$ relato de experiência que ora se apresenta comunga dessa ideia, uma vez que demonstra o quanto a satisfação pode desencadear novas oportunidades e, principalmente, provocar a aperfeiçoamento do indivíduo, à medida que ele busca ampliar seus conhecimentos e, para isso, a dedicação aos estudos é de fundamental importância, sendo que o exercício da docência interfere, intensamente, nessa dedicação.

Dentre as diversas profissões existentes no mercado brasileiro, tem-se a Biblioteconomia, vista por muitos como "uma profissão ultrapassada", ou ainda "uma profissão meramente operacional". É comum percebermos, por parte do mercado de trabalho e na própria academia, a famosa expressão “biblio o quê?". Mas, é preciso desmistificar certos preconceitos a respeito de muitas profissões, sobretudo quanto a essa área de conhecimento que muito se evoluiu nos últimos anos e muito pode contribuir para o desenvolvimento social.

A Biblioteconomia é uma profissão relativamente nova. No entanto, as práticas bibliotecárias datam de tempos imemoriais, desde os primórdios da civilização quando esses tiveram a necessidade de registrar suas práticas, sua historicidade, seus costumes e suas tendências, objetivando garantir a 
perpetuação do conhecimento às gerações futuras.

Devido a sua interação com a preservação e disseminação do conhecimento, a Biblioteconomia estende seus serviços a todas as áreas do conhecimento. É graças a seu poder de integração inter e multidisciplinar que ela adapta-se a diferentes épocas e contextos, tornando-se uma profissão primordial e necessária ao crescimento das demais ciências existentes. Assim, destaca-se a fala de Ortega Y Gasset (2006, p. 67) ao proferir que “[...] essa profissão [a Biblioteconomia] é uma das mais importantes que se pode imaginar".

Devido a seu amplo campo de atuação, a Biblioteconomia encanta. Encanta, principalmente àqueles que se colocam a serviço da disseminação da informação e geração de conhecimentos, no intento de concretizar uma sociedade democrática e cidadã. Conforme relatado por Andrade (1976, p. 36, grifo nosso), “[...] isso é a grandeza admirável da Biblioteconomia! Ela torna perfeitamente acháveis os livros como os seres, e alimpa a escolha dos estudiosos de toda suja confusão. Este o seu mérito grave e primeiro [...]".

Sendo assim, quem se gradua em Biblioteconomia coloca-se a serviço da sociedade, podendo atuar em diferentes instâncias do mercado. Coloca-se a serviço da sociedade, também, aqueles que se dedicam ao exercício da docência, que, a fim de ministrar disciplinas, são forçados a estudar, a exercer as habilidades de leitura e escrita, como também, acabam recebendo uma carga de conhecimento, principalmente se adotar em sala de aula, uma postura democrática, dialógica e pautada na pesquisa, consolidando, junto a seus alunos, práticas de "ensinar aprendendo", conforme discorrido na obra de Freire (2006).

A partir dessas considerações, este texto objetiva relatar as principais atividades desenvolvidas por um bibliotecário recémformado, por meio da docência voluntária, referente ao segundo semestre de 2014, lecionando a disciplina Formação $e$ Desenvolvimento de Coleções, vinculada ao Departamento de Biblioteconomia, de uma universidade federal.

\section{UM BREVE DISCURSO TEÓRICO}

O desenvolvimento de uma carreira profissional não se inicia apenas com o término da formação acadêmica. Ao contrário, deve ser iniciado desde os primeiros contatos e vivências ocorridos na universidade, perpassando toda a vida do profissional, haja vista a necessidade constante de aperfeiçoamento exigida pelo mercado de trabalho da atualidade (REAL et al., 2017).

Essa necessidade se estende a todas as profissões, o que requer, primordialmente, a tomada de consciência do profissional, ainda no decurso de sua formação acadêmica, de modo que ele estabeleça seus objetivos profissionais e as estratégias necessárias para o alcance desses objetivos. Desse modo, é preciso valorizar o planejamento da carreira, pois, dessa forma, aumentam-se as possibilidades de se atingir o sucesso profissional (REAL et al., 2017).

Ressalta-se que o profissional de sucesso é aquele que, além de planejar sua carreira, também constrói e reconstrói, continuamente, suas competências e habilidades. Essa (re)construção é fruto da fusão entre teoria e prática, sendo a primeira alicerçada nos estudos de pesquisa e leitura constantes, atividades essas que permeiam, intensamente, o cotidiano das salas de aula, seja atuando como aluno ou professor (OLIARI et al., 2017).

Assim, a prática docente muito pode contribuir para o aperfeiçoamento profissional, como também, a vivência profissional exerce influências benéficas à formação e capacitação dos docentes. Trata-se de dois processos integralmente relacionados, sendo que a atividade docente, de modo especial, envolve “[...] a construção de saberes que possam servir como instrumento para análise da realidade [e permite] compreender o que há por trás das situações que se depara no cotidiano profissional" (OLIARI et al., 2017, p. 3).

Sendo assim, atuar como docente representa uma estratégia viável, pois é por meio da constante busca por informações no planejamento e condução das aulas, que se alcançam novos olhares, visões, possibilidades, enfim, o profissional que leciona amplia seus conhecimentos, por conseguinte, aprimora suas competências e habilidades que sustentam o fazer profissional (FREIRE, 2007). 
Nesse contexto, pode-se afirmar que a prática docente e profissional, além de estarem atreladas, também deve estar em constante aperfeiçoamento, cabendo ao indivíduo que leciona e/ou que exerce uma profissão, seja ela qual for, ampliar "[...] seus conhecimentos em torno do homem, de sua forma de estar sendo no mundo, substituindo por uma visão crítica a visão ingênua da realidade, deformada pelos especialismos estreitos" (FREIRE, 2007, p. 21).

Especificamente, no que tange à prática docente, Freire (2006) ensina que o professor precisa conscientizar-se de que ensinar não é transmitir conhecimento, mas construir possibilidades para a sua produção ou construção. Dessa forma, a relação entre aluno e professor deve ser dialógica, de compartilhamento de conhecimento, o que evidencia a postura democrática por parte do docente e o método da aprendizagem compartilhada a ser adotado nas salas de aula.

Freire (2006) confirma a interação entre fazer docente e aperfeiçoamento profissional, como também defende a necessidade de reconhecimento acerca dos papéis exercidos por alunos e professores, ao estabelecer três pilares básicos que devem sustentar a prática docente, que são: 1 - consciência de si e do outro; 2 - a corporificação do "eu social" (ser democrático); e 3 - a instrumentalização do fazer profissional (conhecimento teóricoprático).

Em todos os casos, não resta dúvida das contribuições que o exercício da docência poderá viabilizar a ampliação de conhecimento por parte do profissional, o qual poderá tornar-se mais preparado para atuar no mercado de trabalho. Assim, para ser docente é preciso desenvolver algumas competências, como: o domínio da didática, a interdisciplinaridade, a flexibilidade, o uso das tecnologias e o bom relacionamento com os alunos (SANTOS, 2016). Com efeito, segundo a mesma autora, essas competências são plurais e se entrecruzam, contribuindo para o desenvolvimento do indivíduo, de modo que ele seja capaz se atuar no âmago da docência, como também, possa exercer diversas atividades no mercado, ocupando variados campos de atuação.

A docência no ensino superior de Biblioteconomia, conforme relatado no estudo de Diniz e Carvalho (2010), enfrenta alguns desafios, sobretudo no que tange à formação de competências e habilidades de cunho pedagógico. Logo, faz-se necessário qualificar os docentes, por meio de uma formação pedagógica que sustente um ensino de melhor qualidade enquanto instrumento necessário para o exercício da docência.

Por fim, a preparação pedagógica de professores para atuar na docência do ensino superior de Biblioteconomia, como em qualquer área de conhecimento, se justifica, pois, " $[\ldots]$ no processo de ensinar, compete ao professor criar e organizar as condições essenciais para a aprendizagem do discente, o que vai exigir uma assimilação da dimensão pedagógica pelo professor [...]" (DINIZ; CARVALHO, 2010, p. 89).

\section{RELATO DA EXPERIÊNCIA}

A experiência relatada neste texto referese à prática educativa realizada por um bibliotecário, recém-formado, o qual ingressou-se, na mesma universidade onde estudava, ao corpo docente do Curso de Biblioteconomia.

A contratação do professor manifestou-se de forma voluntária, o que não gerou vínculo empregatício, mas uma atividade de prestação de serviços não remunerados. Importante destacar que, nesse tipo de prestação de serviços,

[...] os voluntários não doam somente o seu tempo e sua generosidade, mas respondem a um impulso humano fundamental: a vontade de colaborar, de ajudar, de dividir alegrias, aliviar sofrimentos e de melhorar a qualidade da vida em comum. Solidariedade, responsabilidade e compaixão são sentimentos essencialmente humanos e virtudes cívicas (MAIA, 2017, p. 1).

Portanto, a atuação do docente sustentouse em dois motivos: 1 - ajudar a universidade, em virtude do afastamento de professores efetivos para o processo de doutoramento, e 2 - ampliar seus conhecimentos relativos à Biblioteconomia, de modo que se tornasse mais capacitado para atuar no mercado de trabalho. Além desses dois motivos, também é importante ponderar acerca dos benefícios que o professor teria, em termos de qualificação acadêmica, pois, essa experiência poderia credibilizá-lo, de alguma forma, sobretudo no que tange à participação, $a$ posteriori, em processos seletivos para 
contratação de professor e outros cargos relacionados ao exercício docente.

\subsection{DA CONTRATAÇÃO DE PROFESSOR VOLUNTÁRIO: ASPECTOS LEGAIS}

No contexto institucional em que se desenvolveu os serviços de docência universitária voluntária apresentados neste relato, a contratação desse tipo de atividade é regulamentada por meio de resolução administrativa determinada pelo conselho universitário da instituição de ensino.

A resolução número 01 de 2012 contitui um documento legal estabelecido pelo Centro de Ciências Jurídicas e Econômicas da Universidade Federal do Espírito Santo e tem como principal objetivo regulamentar a seleção e atribuição de encardos didáticos a docentes do Programa de Prestação de Serviço Voluntário no contexto desse centro de ensino (UNIVERSIDADE FEDERAL DO ESPÍRITO SANTO, 2012).

Consta no Art. $1^{\circ}$ dessa resolução que a seleção de docente para atuar, em nível de graduação, dependerá de aprovação prévia do candidato em processo seletivo, conduzido por banca examinadora, seguindo a regras do Título III da Resolução $n^{\circ}$. 41/2011 do Conselho de Ensino, Pesquisa e Extensão da universidade, que estabelece as normas para contratação de professor substituto (UNIVERSIDADE FEDERAL DO ESPÍRITO SANTO, 2012).

Ainda sobre o planejamento do processo de contratação, a referida resolução menciona em seu Art. $2^{\circ}$ que deverá ser aprovado pela câmara departamental proponente o número de vagas, a área para a seleção e a titulação que deverá ser, preferencialmente, no mínimo, a de mestre. Além disso, está disposto no parágrafo único desse Art. que, excepcionalmente poderá atuar como professor voluntário o docente portador do título de bacharel ou especialista, mediante justificativa do departamento proponente (UNIVERSIDADE FEDERAL DO ESPÍRITO SANTO, 2012).

Tendo como respaldo legal as normas contidas na resolução 01 de 2012, o Departamento de Biblioteconomia, pertencente ao Centro de Ciências Jurídicas e Econômicas, da Universidade Federal do Espírito Santo, publicou edital específico para contratação do docente voluntário.
3.2 DA VINCULAÇÃO DO PROFESSOR E FORMAÇÃO DA TURMA

O referido professor/bibliotecário foi selecionado por meio de processo seletivo realizado pelo Departamento do Curso de Biblioteconomia, a fim de atuar no lecionamento da disciplina Formação $e$ Desenvolvimento de Coleções, disciplina essa ofertada no sétimo (penúltimo) período do curso em questão.

O processo de seleção foi conduzido por meio de duas etapas: prova de títulos (considerando aspectos relativos à experiência profissional, como também, quantidade de trabalhos publicados) e prova didática. Importante considerar que, no decorrer da Graduação do professor, enquanto aluno, ele havia atuado durante mais de dois anos, no setor de aquisição da biblioteca universitária, fato esse que o qualificou frente às atividades que permeiam o processo de formar $\mathrm{e}$ desenvolver acervo em uma biblioteca.

Após aprovação no processo de seleção e cumprimento aos dispositivos administrativos, o professor iniciou as atividades de lecionamento no dia 27 de agosto de 2014. Como fio condutor das atividades a serem desenvolvidas na disciplina, foi aproveitado o Plano de Disciplina dos semestres anteriores, considerando-se a consistência e metodologia delineada no plano. Foram realizadas apenas pequenas inserções no programa, após aprovação da Câmara Departamental, referente a novas bibliografias a serem utilizadas.

Obedecendo ao calendário acadêmico da universidade, as aulas foram realizadas de 27 de agosto a três de dezembro, sendo oferecidas, nas quartas e sextas-feiras, das 20 às 22 horas, conforme plano de horários definidos pelo Departamento.

Quanto ao número de discentes, em um primeiro momento, estavam matriculados na disciplina, 28 alunos, sendo ampliado para 31 após o processamento da segunda etapa de matrícula. Também foi solicitada a autorização junto ao professor para abertura de escopo para três alunos do curso de Arquivologia, o que foi oficialmente autorizado e concretizado. Após processamento de matrículas, a turma esteve composta por 34 discentes.

A disciplina Formação e Desenvolvimento de Coleções aborda assuntos necessários à 
prática bibliotecária em unidades de informação, sejam elas físicas ou digitais. Especificamente, essa disciplina viabiliza aos discentes a possibilidade de conhecerem as estratégias para formar e desenvolver com qualidade as coleções bibliográficas.

Destaca-se que o processo de formar e desenvolver coleções teve suas origens com a formação dos primeiros acervos, ainda no período da Antiguidade, por meio da atividade de colecionar, realizada por bibliófilos (WEITZEL, 2012). Porém, é apenas no final do século XX que essas atividades adquiriram um aspecto científico, transformando-se em disciplina, tendo como um de seus principais objetivos proporcionar uma visão geral da unidade de informação, de modo a contribuir no planejamento de recursos informacionais (VERGUEIRO, 1989).

Assim, a disciplina, indiretamente, relaciona-se com as demais disciplinas do curso, sobretudo, àquelas ligadas à organização e disseminação da informação, tendo em vista, concretizar cientificamente a gestão das coleções que são incorporadas aos acervos das unidades de informação.

\subsection{DOS CONTEÚDOS ABORDADOS E ATIVIDADES REALIZADAS NA DISCIPLINA}

Tendo como base os conteúdos programáticos da ementa curricular, a disciplina foi dividida em três unidades. Em linhas gerais, essas unidades objetivam demonstrar como assuntos centrais: unidade 1: conceitos e história do desenvolvimento de coleções (aspectos teóricos e epistemológicos); unidade 2: processos e métodos utilizados para desenvolver coleções (aspectos teóricos); unidade 3: formalização do processo de desenvolvimento de coleções (aspectos teóricos e práticos).

Em cada unidade, foram indicadas bibliografias básica e complementar para os alunos, de modo que os assuntos discorridos pudessem ser analisados, como também, permitissem o aprofundamento dos assuntos (bibliografia complementar). Esses materiais indicados contemplaram livros e artigos científicos que versam sobre os assuntos inerentes em cada unidade. $O$ quadro 1 sintetiza os principais conteúdos abordados em cada unidade, como também, aponta as principais bibliografias utilizadas.

Quadro 1: Divisão das unidades da disciplina e principais conteúdos e referenciais utilizados

\begin{tabular}{|c|c|c|c|}
\hline Unidade & Nome da unidade & $\begin{array}{l}\text { Principais conteúdos } \\
\text { programáticos }\end{array}$ & $\begin{array}{c}\text { Principais referenciais teóricos } \\
\text { estudados }\end{array}$ \\
\hline $\mathbf{I}$ & Gestão de coleções & $\begin{array}{l}1 \text { - Aspectos conceituais da } \\
\text { gestão de coleções } \\
2 \text { - Evolução histórica }\end{array}$ & $\begin{array}{l}\text { MARTINS, Wilson. A palavra escrita: } \\
\text { história do livro, da impressa e da } \\
\text { biblioteca. São Paulo: Saraiva, } 2001 \text {. } \\
\text { MIRANDA, A. C. C. Desenvolvimento } \\
\text { de coleções em bibliotecas Universitárias. } \\
\text { Revista Digital de Biblioteconomia e } \\
\text { Ciência da Informação, Campinas, v. 4, } \\
\text { n. 2, p. 01-19, jan./jun. } 2007 \text {. }\end{array}$ \\
\hline II & $\begin{array}{l}\text { Processualidades para } \\
\text { formação e } \\
\text { desenvolvimento de } \\
\text { coleções }\end{array}$ & $\begin{array}{l}\text { 1- Planejamento e } \\
\text { metodologias } \\
2 \text { - Estudo da comunidade } \\
3 \text { - Processos de seleção } \\
4 \text { - Aquisição } \\
5 \text { - Avaliação } \\
6 \text { - Desbaste }\end{array}$ & 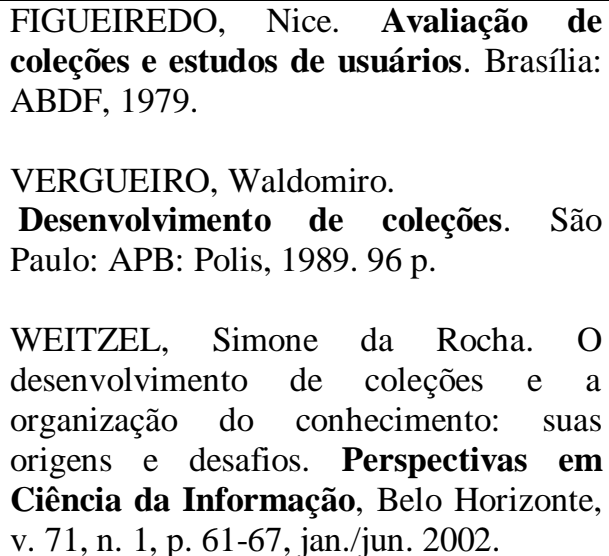 \\
\hline III & $\begin{array}{l}\text { Política de } \\
\text { desenvolvimento de } \\
\text { coleções como }\end{array}$ & $\begin{array}{l}1 \text { - Políticas de acervos } \\
2 \text { - Políticas de informação } \\
3 \text { - Planejamento e }\end{array}$ & $\begin{array}{l}\text { LANCASTER, Frederic. Avaliação de } \\
\text { serviços de bibliotecas. Brasília: Briquet } \\
\text { de Lemos, } 1996 \text {. }\end{array}$ \\
\hline
\end{tabular}


Relatos de Experiência

\begin{tabular}{|l|l|l|lc|}
\hline \hline & política de & implementação & WEITZEL, Simone da Rocha. & da \\
& informação & & $\begin{array}{l}\text { Elaboração de uma política de } \\
\text { desenvolvimento de coleções em } \\
\text { bibliotecas universitárias. Rio de } \\
\end{array}$ & \\
& & Janeiro: Interciência, 2006. & de \\
\hline
\end{tabular}

Fonte: o autor (2014).

Conforme demonstrado no Quadro 1, percebe-se o delineamento dos conteúdos agrupados em cada uma das unidades. Essa separação faz-se necessária, pois permite ao alunado, fixar os conteúdos, de forma processual, facilitando o aprendizado e a avaliação, os quais devem ser conduzidos, também, de maneira processual, conforme relatado por Silva Filho et al. (2012).

No que se referem às atividades acadêmicas realizadas no decurso dessas unidades, elas foram das mais diversificadas, pois, dessa forma, as aulas tornavam-se mais dinâmicas e flexíveis, de modo a motivar o alunado a participar das atividades, sentindose comprometido com a disciplina, ou seja, como dizia Freire (2006), tanto aluno quanto professor, são vistos como partícipes do processo de produção de conhecimento na sala de aula.

Sendo assim, foi solicitada aos alunos, a leitura de artigos e livros que abordam o processo de formação e desenvolvimento de coleções, até visitas técnicas e pesquisas de campo. Não resta dúvida de que a leitura da bibliografia básica representou uma das maiores exigências da disciplina, acompanhada também da leitura de artigos científicos publicados em revistas da Ciência da Informação, na qual retratam temas correlatos à Gestão das Coleções. Como estratégia de motivação da leitura textual adotaram-se estudos dirigidos, trabalhos em grupos e rodas de conversa.

As atividades de pesquisa foram utilizadas como estratégia para desenvolver a competência informacional nos discentes, além do espírito crítico em argumentar as ideias. Assim, questões problematizadoras eram levantadas e os discentes eram motivados a encontrar soluções científicas, no intuito de tornarem-se capacitados a gerenciar processos e tomar decisões, atividades fins atreladas ao processo de formar e desenvolver coleções.

A relação teoria-prática também foi essencial nessa disciplina, visto que seu objetivo é capacitar os alunos para assumir com competência a gerência de unidades de informação. Para tanto, consolidou-se as visitas técnicas, sendo uma realizada no Setor de Aquisição da biblioteca universitária e outra realizada no Setor de Desbastamento (baixa demanda) da mesma unidade. Visando aprimorar as atividades práticas, foram realizados estudos de campo, em diferentes modalidades de bibliotecas, com vista a visualizar na prática como os processos recomendados pela literatura eram concretizados no âmbito real.

Em síntese, podem-se citar como principais procedimentos de ensino, a saber: aulas expositivas, orientações individuais e em grupo, análise e discussão de trabalhos, estudos de casos, análise de políticas de desenvolvimento de coleções e apresentação de seminário. Quanto às atividades discentes, destacam-se as principais: leitura, discussão e redação de textos, visitas técnicas, seminários, estudo dirigido e exercícios (questões objetivas).

Importante destacar que essas atividades diversificadas, de um modo geral, estiveram pautadas no método estabelecido por Paulo Freire (2006), haja vista desenvolver uma prática educativa conduzida pelo diálogo e pela aprendizagem compartilhada. Segundo Freire (2006, p. 67), a educação dos novos tempos deve ser comprometedora e libertadora. Assim,

A educação que se impõe aos que verdadeiramente se comprometem com a libertação não pode fundamentar-se numa compreensão dos homens como seres 'vazios' a quem o mundo 'encha' de conteúdos; não pode basear-se numa consciência espacializada, mecanicistamente compartimentada, mas nos homens como 'corpos conscientes' e na consciência como consciência intencionada ao mundo. Não pode ser a do depósito de conteúdos, mas a da problematização dos homens com o mundo $[\ldots]$.

Esses procedimentos de ensino foram esclarecidos ao alunado, no primeiro dia de aula, em que foi esplanada toda a ementa da 
disciplina, com destaque nas atividades realizadas. $\mathrm{O}$ professor voluntário decidiu adotar essa metodologia de ensino, pois acredita que, ao mesmo tempo que ensinava, estaria aprendendo com seus alunos. Logo, a disciplina seria sustentada pelo diálogo, pelo compartilhamento de informações e pelo respeito, consolidando uma prática democrática, como ensinado por Freire (2006).

Atrelado a isso, os alunos realizaram atividades de pesquisa, normalmente de forma coletiva (em grupos), e os resultados das pesquisas (sejam elas teóricas quanto práticas) foram socializadas em sala, por meio da prática de seminários e rodas de conversa. Em virtude dessa interação entre alunos e professor, a disciplina não teria avaliação formal (por escrito), como de costume, mas os trabalhos escritos e a apresentação deles seriam avaliados, considerando diversos critérios predeterminados.

Com efeito, a prática da pesquisa no âmbito da disciplina Formação $e$ Desenvolvimento de Coleções teve como fundamento, a filosofia de Paulo Freire, que, segundo esse autor,

Não há ensino sem pesquisa e pesquisa sem ensino. Esses que-fazeres se encontram um no corpo do outro. Enquanto ensino continuo buscando, reprocurando. Ensino porque busco, porque indaguei, porque indago e me indago. Pesquiso para constatar, constatando, intervenho, intervindo, educo e me educo. Pesquiso para conhecer e o que ainda não conheço e comunicar ou anunciar a novidade (FREIRE, 2006, p. 15).

Destarte, o professor pretendeu, por meio dessas metodologias, estimular os alunos à autocrítica, utilizando, sobremaneira, o hábito da leitura e da investigação. Isso se deve pelo docente acreditar que o método freireano seja o mais adequado nos dias atuais, como também, os conteúdos da própria disciplina exigem a atividade investigativa, por abarcar muitos conceitos, teorias, fundamentos $\mathrm{e}$ historicidade. Ademais, o professor também acreditava que esses procedimentos seriam úteis e adequados ao contexto ou realidade dos alunos, visto que o alunado se encontrava em fase inicial das atividades investigativas para produção dos trabalhos de conclusão de curso.

\subsection{DOS RECURSOS DIDÁTICOS $\mathrm{E}$ PROCEDIMENTOS AVALIATIVOS}

Para que a atividade educativa seja realizada, não resta dúvida acerca das contribuições desempenhadas pelos recursos didáticos, conceituados, segundo Magalhães (2012), como objetos utilizados em prol de uma aprendizagem qualitativa. Para esse autor, a classificação de um instrumento qualquer em recurso didático depende da criatividade do educador em utilizar este ou aquele objeto para ajudar o aluno a compreender determinado tema em estudo.

No caso específico da experiência aqui relatada, para que as atividades oferecidas pelo professor alcançassem o objetivo maior, que era proporcionar o ensino-aprendizagem de qualidade ao alunado, além de despertá-los para a prática da pesquisa, compartilhamento de informações e autorreflexão, foram utilizados diversos recursos didáticos, em consonância com a realidade da instituição. Assim, o quadro 2 demonstra os principais recursos utilizados em cada unidade, considerando as atividades principais realizadas em cada uma delas.

Quadro 2: Recursos didáticos utilizados em cada unidade, com base nas atividades principais de cada unidade

\begin{tabular}{|l|l|l|}
\hline \multicolumn{1}{|c|}{ Unidade } & \multicolumn{1}{|c|}{ Atividades centrais } & \multicolumn{1}{|c|}{ Principais recursos utilizados } \\
\hline I - Gestão de coleções & $\begin{array}{l}\text { Pesquisa, leitura e resumos sobre } \\
\text { assuntos específicos e apresentação } \\
\text { de trabalhos }\end{array}$ & $\begin{array}{l}\text { Lousa e giz, projeto multimídia, } \\
\text { filmes, vídeos e textos científicos }\end{array}$ \\
\hline $\begin{array}{l}\text { II - Processualidades do } \\
\text { desenvolvimento de coleções }\end{array}$ & Visitas técnicas & $\begin{array}{l}\text { Laboratório de processamento } \\
\text { técnico de documentos }\end{array}$ \\
\hline III - Polícias de informação & $\begin{array}{l}\text { Coleta de dados em contextos reais } \\
\text { (diferentes modalidades de } \\
\text { bibliotecas) }\end{array}$ & $\begin{array}{l}\text { Pesquisa via questionário, visita } \\
\text { in locu }\end{array}$ \\
\hline
\end{tabular}

Fonte: dados da pesquisa (2015). 
Importante pontuar que, os dados contidos no Quadro 2, principalmente a descrição das atividades realizadas, dizem respeito às atividades centrais, ou seja, as atividades mais importantes, que demandaram mais esforço pelos alunos, como também provocou algo inovador na prática educativa. Todavia, atrelado a essas atividades, outras foram realizadas, por conseguinte, outros recursos também foram utilizados, com destaque especial para as pesquisas, leituras, resumos e apresentações de assuntos investigados, atividades essas que estiveram presente em todas as unidades da disciplina, e o uso da lousa, giz, projetor multimídia e textos científicos, os quais representaram recursos didáticos inerentes a todas as unidades.

Quanto ao processo avaliativo, conforme expresso no programa da disciplina, foram utilizados os seguintes critérios:

- Domínio Cognitivo $(85 \%$ da classificação final): avaliou as capacidades de raciocínio e organização de conhecimentos através de testes somativos sobre os conteúdos ministrados e trabalhos escritos;

- Domínio das atitudes e valores (10\% da classificação final): avaliou a situação do aluno no processo de ensinoaprendizagem através da assiduidade e pontualidade (nível de assiduidade e pontualidade nas aulas), empenho e motivação (nas atividades letivas solicitadas), comportamento e relação com os outros (adequação do aluno às regras de funcionamento das atividades letivas e respeito aos colegas e professor);

- Domínio das Aptidões/Capacidades (5\% da classificação final): avaliou a aplicação dos conhecimentos através da expressão escrita e oral (integração dos conteúdos no discurso e rigor de terminologia escrita e oral) e autonomia na aprendizagem (capacidade de iniciativa, aplicação dos conteúdos a novas situações).

Além desses parâmetros, durante as aulas, os discentes eram monitorados, motivados a participar, a pesquisar, por conseguinte, esses pormenores constituíram atribuição de pontos a serem somados na média final. É importante enfatizar que, a avaliação dos alunos considerou o desenvolvimento do aprendizado durante toda a disciplina, baseando-se na troca coletiva, mas individualizando cada aluno em suas experiências prévias e sua construção de conhecimento.

Por meio do fazer educacional pautado na pesquisa e no compartilhamento, não resta dúvida acerca dos benefícios proporcionados ao alunado, principalmente no que se refere a sua formação profissional e necessidade de buscar melhorias contínuas nas atividades que realiza. Assim, o ensino na sala de aula tende a repercutir no exercício profissional. Logo,

O desenvolvimento de capacidades e habilidades de pensar e aprender estruturados dentro de um ambiente adequado é necessário para promover mudanças e inovações, levando a uma melhoria significativa dentro de sala de aula. Os cursos de ensino superior devem dar o suporte para os novos profissionais e cidadãos. Somente com a prática e desenvolvimento da atividade intelectual realizada de forma concreta e participativa tem-se a formação do ser integral [...] (GONÇALVES; SIQUEIRA, 2017, p. 1, grifo nosso).

Desse modo, o processo avaliativo, embora tenha como produto final a aferição de um valor (nota), esse quantitativo foi eleito a partir da análise qualitativa a diferentes critérios, de modo que, conforme defendido por Luckesi (2002), o professor não assume uma postura de examinar, em que pese, tão somente, o estabelecimento de números (notas). Ao contrário, em um contexto de educação democrática, esse profissional precisa analisar as circunstâncias de cada aluno, e com base em uma medida, estabelecer estratégias contínuas que assegurem a melhoria do aprendizado.

\section{CONSIDERAÇÕES FINAIS}

Este texto relatou o exercício do magistério exercido por um bibliotecário recém-formado, considerando o contexto ou circunstâncias a que se manifestou essa experiência, tal como a vinculação do professor, como prestador de serviços voluntários, os conteúdos abordados e as atividades realizadas na disciplina ministrada Formação e Desenvolvimento de Coleções e, por fim, os principais recursos $\mathrm{e}$ procedimentos avaliativos que permeou a prática educativa.

Optou-se por utilizar, ao longo da disciplina, a filosofia determinada por Paulo 
Freire, cuja postura do professor considera o diálogo, compartilhamento de informações e $\mathrm{o}$ ato da pesquisa como principais estratégias para melhorar o ensino-aprendizagem, tornar os alunos motivados, além de desenvolverlhes autorreflexão e crítica da realidade, de modo a interferir na postura do profissional frente ao mercado de trabalho.

Por meio desse método, percebeu-se, ao final da disciplina, a satisfação dos alunos, como também o engajamento com as atividades investigativas, aumento da capacidade inovadora, argumentativa e decisória, fato esse que confirmou a importância da prática docente na formação do futuro profissional.

Como prova dos esforços despendidos em sala de aula de ambas as partes e como resultado dessa experiência, as discussões em sala permitiu a escrita de um artigo, de cunho teórico, sobre o processo de formação e desenvolvimento de coleções, cujos resultados preliminares desse estudo foram apresentados, em 2014, no $18 .^{\circ}$ Seminário de Bibliotecas Universitárias, que aconteceu em Belo Horizonte, e os resultados finais foram publicados, em 2016, como artigo completo, na Revista Biblionline ${ }^{1}$.

Além desses pontos positivos para com o alunado, percebeu-se, também, que o exercício da docência voluntária agregou valor na capacitação do docente/bibliotecário voluntário ao viabilizar o compartilhamento de conhecimentos, reciprocamente com os discentes da disciplina e demais docentes do Curso de Biblioteconomia da universidade. Evidenciou-se que o conhecimento adquirido coletivamente contribuiu no crescimento de ambas as partes, tanto do docente quanto do alunado. Importante confirmar que esse crescimento foi possível, pois a atividade docente e a metodologia utilizada, permeada

$1 \mathrm{O}$ artigo intitulado "Desenvolvimento de Coleções e o Sistema de Bibliotecas da UFES: comparativo entre os modelos teóricos de Evans e Baugman e a adequação ao modelo de Evas", foi elaborado pelo professor bibliotecário voluntário durante seu período de estágio no setor de aquisição da biblioteca universitária e diante das leituras da bibliografia básica realizadas no período da docência voluntária na disciplina de Formação e Desenvolvimento de Coleções. Acesso ao artigo completo pelo endereço: $<$ http://periodicos.ufpb.br/ojs2/index.php/biblio/ar ticle/view/27933>. por práticas constantes de leitura, pesquisa e embasamento teórico e prático - práticas diluídas no processo de planejamento e preparação das aulas - condicionou a ampliação de competências e habilidades.

No que tange ao aprendizado adquirido pelo professor-bibliotecário, constatou-se a ampliação de conhecimento, uma vez que o método utilizado pautou-se nas propostas freireanas, em que o conhecimento deve ser socializado de forma dialógica, integrada, democrática e recíproca. A relação dialógica firmada com os alunos permitiu a (re)construção de valores e de opiniões por parte do conhecimento prévio dominado pelo docente-bibliotecário.

A experiência vivenciada nessa docência voluntária contribuiu para o crescimento profissional do docente-bibliotecário, sobretudo no que se refere à atuação em consultoria informacional, ramo principal exercido pelo referido docente no mercado de trabalho. Constatou-se a assimilação acerca das teorias que fundamentam o processo de formação e desenvolvimento de coleções, bem como os pormenores que envolvem essa prática bibliotecária. 


\title{
Abstract
}

\begin{abstract}
Librarianship is an area of knowledge that enchants. This is justified for several reasons. It is worth highlighting the fact that professional librarianship permeates all other areas of knowledge, contributing to the organization and dissemination of information produced in any scientific field, which naturally makes it possible for the librarian to acquire a variety of knowledge. From this statement, this article reports the beginning of the professional career of a librarian, through his role as a volunteer teacher. It discusses the context of the teacher's attachment to the Library Course, as well as the didactic resources, the teaching procedures adopted and the activities carried out in the classroom, through the lecturing of the Training and Development of Collections discipline. At the end, it testifies to the contributions of the experience, mentioning the benefits achieved by both the teacher and the student and expectations for entry into the job market.
\end{abstract}

Keywords:Teaching-Librarianship. Teaching by research. Professional practice. Collection management.

\section{REFERÊNCIAS}

ANDRADE, Mario. Os filhos da Cândinha. São Paulo: Martins, 1976.

DINIZ, Edileuda Soares; CARVALHO, Ademar de Lima Carvalho. Aprendizagem profissional: a docência na biblioteconomia. Encontro Bibli: Revista Eletrônica de Biblioteconomia e Ciência da Informação, Florianópolis, v. 15, n. 30, p.74-90, 2010. Disponível em: $<$ https://periodicos.ufsc.br/index.php/eb/articl e/viewFile/1518-

2924.2010v15n30p74/19531>. Acesso em: 13 nov. 2017.

FREIRE, Paulo. Pedagogia da autonomia: saberes necessários à pratica educativa. 33 . ed. São Paulo: Paz e Terra, 2006.

. Educação e mudança. 30 ed. Rio de Janeiro: Paz e Terra, 2007.

GONÇALVES, Cristiane Maria Barcelos; SIQUEIRA, Lisarda de Moraes Cardoso. Docência no ensino superior: identidade, prática e profissão docente. 2017. Disponível em: <http://www.cnsd.com.br/artigos/828docencia-no-ensino-superior-identidadepratica-e-profissao-docente>. Acesso em: 13 nov. 2017.

LUCKESI, Cipriano Carlos. Avaliação da aprendizagem escolar. 14 ed. São Paulo: Cortez, 2002.
MAGALHÃES, Altina Costa. Recursos didáticos no processo de aprendizagem: conceitos, funções, possibilidades e limitações. 2010. Disponível em:

<https://www.webartigos.com/artigos/recurso s-didaticos-no-processo-de-aprendizagemconceito-funcao-possibilidades-elimitacoes/84480/>. Acesso em: 13 nov. 2017.

MAIA, Milena. A importância do trabalho voluntário para a sociedade. 2017.

Disponível em:

<http://www.amambainoticias.com.br/geral/ar tigos/a-importancia-do-trabalho-voluntariopara-a-sociedade>. Acesso em: 13 nov. 2017.

OLIARI, Fátima Albertina Sangaletti et al. Refletindo sobre a identidade e a formação do professor da educação superior. 2017. Disponível em:

$<$ http://www.unifia.edu.br/revista_eletronica/r evistas/educacao foco/artigos/ano2012/refleti ndo sobre identidade.pdf $>$. Acesso em: 13 nov. 2017.

ORTEGA Y GASSET, José. Missão do bibliotecário. Brasília: Briquet de Lemos, 2006.

REAL, Juliana de Oliveira Villa et al. Desenvolvimento da Carreira:

Responsabilidade da organização ou responsabilidade do indivíduo? 2017. Disponível em:

$<$ http://www.ucs.br/etc/conferencias/index.ph 
p/mostraucsppga/mostrappga2013/paper/view File/3620/1102>. Acesso em: 13 nov. 2017.

SANTOS, Camila de Fátima Soares dos. Formação pedagógica: contribuições e desafios na docência universitária. 2016. Disponível em:

<http://www.anpedsul2016.ufpr.br/wpcontent/uploads/2015/11/EIXO6_CAMILADE-F\%C3\%81TIMA-SOARES-DOSSANTOS.pdf>. Acesso em: 13 nov. 2017.

SILVA FILHO, José Amadeu da et al. Avaliação educacional: sua importância no processo de aprendizagem do aluno. Realize, Campina Grande, 2012. Disponível em: <http://editorarealize.com.br/revistas/fiped/tra balhos/f7b399b81548477eec9e94f5cfccffc7 1919.pdf>. Acesso em: 13 nov. 2017.

UNIVERSIDADE FEDERAL DO ESPÍRITO SANTO. CENTRO DE CIÊNCIAS JURÍDICAS E ECONÔMICAS. Resolução

n. 01 de 2012. Regulamenta a seleção e atribuição de encargos didáticos a docentes do Programa de Prestação de Serviço Voluntário da UFES no âmbito do Centro de Ciências Jurídicas e Econômicas em Cursos de Graduação. Disponível em:

$<$ http://www.ccje.ufes.br/sites/ccje.ufes.br/file s/field/anexo/resolucao_n._01.2012_-

regulamenta atividade de professor volunt ario.pdf>. Acesso em: 12 jan. 2018.

VERGUEIRO, Waldomiro.

Desenvolvimento de coleções. São Paulo: Polis: APB, 1989.

WEITZEL, Simone Rocha. Desenvolvimento de coleções: origem dos fundamentos contemporâneos. TransInformação, Campinas, v. 24, n. 3, p. 179-190, set./dez. 2012. Disponível em: <http://www.scielo.br/pdf/tinf/v24n3/a03v24 n3.pdf>. Acesso em: 13 nov. 2017. 